\title{
AVALIAÇÃO DA APRENDIZAGEM E Progressão CONTINUADA: bases para construção de uma nova escola
}

\author{
ZILMA DE MORAES RAMOS DE OLIVEIRA ${ }^{1}$
}

A Lei $9394 / 96$, ao estabelecer as diretrizes e bases da educaçăo nacional, buscou criar condições legais para que cada escola pudesse se organizar para o alcance dos objetivos propostos na Constituição de 1988 em relação à educação e que espelham o anseio da Sociedade brasileira de ter educados todos os seus cidadãos, zelando por medidas de não-exclusão de alunos pelo sistema escolar, quer pela garantia de vagas, quer pela efetivação de uma aprendizagem bem sucedida.

Respondendo a este desafio, tem sido defendida a necessidade de se substituir uma concepçăo de avaliaçăo escolar punitiva e excludente por uma concepção de avaliação comprometida com o progresso e o desenvolvimento da aprendizagem.

A avaliação tem sido tradicionalmente usada na escola para orientar a organização de turmas, dentro de um modelo educacional que pressupōe uma única competência básica a ser dominada por todos os alunos em um mesmo período de tempo. Quem não o fizesse, seria apartado da turma e impedido de mover-se para série seguinte (pró-mover-se). Esta retenção do aluno na série que cursou durante determinado período escolar termina, no imaginário que ainda existe nas escolas, fazendo o aluno sentir-se como alguém reprovado, no sentido de rejeitado, excluído, condenado, censurado, com sérias conseqüências para a auto-estima e futuras aprendizagens.

Todavia, voltar a cursar uma série com o desgaste emocional de perder sua turma e parte de sua identidade, e ficar vendo as mesmas questōes apresentadas no mesmo jeito pelos professores, pode ser bem mais deseducativo do que promotora de aprendizagem. Com as

Chefe de Gabinete da Secretaria do Estado da Educaçáo de Săo Paulo, Membro do Conselho Estadual de Educação, Professara dos Programas de Pós-graduaçăo da FEUSP e da FFCLRP de Ribeiråo Preto-USP. 
sucessivas e desestimulantes retençōes dos alunos no percurso escolar, estes encontram outros meios de inserir-se no social, ou de colocar-se neste contra essa estrutura. A não-promoção tem sido, assim, a maior aliada da evasăo escolar e, portanto, da exclusão do direito à Educação que toda sociedade busca garantir.

$O$ instituto da progressão continuada baseia-se nestas consideraçōes. Ele foi previsto na LDB - Lei de Diretrizes e Bases da Educação Nacional (Lei 9394/96 artigo 32 parágrafo segundo) e normatizado pela Deliberaçăo 9/97 do Conselho Estadual de Educação de São Paulo. Seu caráter inovador necessita ser discutido para elucidar sua compreensão pelos educadores e pais, estimulando-os a sair da redoma das concepçōes sobre a educação escolar ainda existentes nas escolas, embora pouco conscientes por parte dos atores sociais envolvidos e que são extremamente cristalizadas.

A presença da progressão continuada leva os professores a analisar suas concepçōes sobre o papel e as finalidades do ensino fundamental na sociedade brasileira contemporanea e o significado do processo de aprendizagem de seus alunos. Para muitos professores, diretores e famílias, herdeiros da tradição criada pela estrutura elitista $\mathbf{e}$ excludente da escola brasileira, a organizaçăo escolar em ciclos, os quais, por definiçăo, năo comportam retenções em seu interior, não pode ser produtiva para a aprendizagem dos alunos. Contudo, dados de pesquisa têm apresentado que as aprendizagens se fazem por espirais e que mesmo que algumas aquisiçōes fiquem prejudicadas por um certo período enquanto se desenvolve o complexo processo de ensino, a não-retenção dos alunos na progressăo continuada pode permitir mais avanços do que quando é defendido um ritmo homogêneo e linear de domínio de conteúdos escolares.

Assim a progressão continuada não se alia de forma alguma com possível rebaixamento do ensino, antes envolve pensar sempre em diversas formas de prover aprendizagens essenciais, com o domf́nio de habilidades e atitudes de busca de novas informaçōes e conhecimentos, de cooperação etc., através de um projeto consistente de trabalho pedagógico elaborado e desenvolvido em equipe.

Há desta forma um pensar pedagógico que valoriza o aprendido enquanto investiga que outras circunstâncias na vida escolar atuariam sobre os alunos, levando-os a avançar em seu aprendizado escolar. Para tanto faz-se mister que a organização escolar realize contínuas avaliações parciais da aprendizagem e recuperaçōes paralelas durante todos os períodos letivos, dado que o compromisso da escola com a 
aprendizagem dos alunos só termina quando todos os recursos para que eles aprendam foram usados.

Para cada aluno com baixo aproveitamento escolar em relaçăo à turma, a escola precisa colocar à disposiçåo dos pais e órgâos de supervisăo os resultados de suas avaliaçôes (muito menos notas ou mençōes, mas principalmente consideraçōes sobre as dificuldades de aprendizagem do aluno), seu desempenho em relação ao grupo e todas as providências adotadas na busca da recuperação de sua aprendizagem.

Se uma escola envidou todos os esforços para que o aluno aprenda, através de recuperaçōes contínuas e paralelas, e isto não ocorreu, cumpre investigar o que estaria acontecendo com este aluno nesta escola e que o tornou impossibilitado de aprender, e propor alternativas de ação pedagógica para garantir sua aprendizagem. É muito difícil, todavia, imaginar que um aluno esteja sem aproveitamento algum, tendo freqüentado aulas coordenadas por seus professores. Se situaçőes como esta săo comuns em uma determinada escola, há que se refletir sobre o que se passa com a proposta de trabalho pedagógico da mesma e buscar soluçōes para os problemas nela vividos.

Os alunos que precisam de mais tempo para aprender e os com dificuldades específicas, mas que já avançaram mesmo que seja um pouco sua aprendizagem, não podem ser prejudicados com a perda da turma de amigos que the dão apoio emocional. No regime de progressåo continuada, aquele que, nas séries de um ciclo, exceto a última, apresente um aproveitamento escolar insuficiente em relação ao que foi estabelecido, é classificado para a série seguinte acompanhado por um conjunto de medidas pedagógicas - estudos suplementares já durante as férias de verăo e recuperaçăo paralela pelo tempo que se fizer necessário, dentro do projeto pedagógico da escola - que lhe garantam a apropriação dos conhecimentos sistematizados que a escola escolheu trabalhar.

Observados os progressos feitos, ainda que pequenos, e especialmente as condiçōes em que estes foram feitos, pode-se planejar os próximos passos, exigindo novas atitudes do aluno, da família e, inclusive, da escola. Năo se coloca assim a aprovaçăo sem critério, sem um diagnóstico pedagógico, sem um sério plano de trabalho a ser vencido nos anos posteriores, mera promoção automática. 
Ao final de cada ciclo, uma avaliaçăo do desenvolvimento e da aprendizagem dos alunos pode considerar eventualmente a necessidade de um programa sistematizado e individualizado de apropriação de conteúdos básicos propostos para o ciclo e que um aluno ainda năo dominou, por um período de até um ano escolar.

Quanto ao argumento de que muitos alunos não aprendem pois apresentam atitudes de não-envolvimento com a aprendizagem e mesmo indisciplina, é necessário considerar quantos são estes, que dinâmica os orienta e em que série trabalharn. Atravessariam eles alguma situação individual de risco maior: gravidez indesejada, uso de drogas, problemas no emprego ou em casa? Estariam sendo as atividades propostas suficientemente interessantes para os desafiar? Diante de provocações que săo por vezes observadas na relação que se estabelece entre o professor e seus alunos, particularmente os mais velhos, ao invés de pensar em revidar com fortes punições, cabe aos educadores refletir de que forma pedagogicamente válida lidar com os conflitos cotidianos de autoridade existentes na escola, e que aparecem sob forma de desobediência às orientaçōes docentes, de modo a aprofundar o conceito de cidadania năo só do aluno mas também do professor?

Em relaçăo a outro segmento do alunado que tem sido lembrado quando se discute a progressăo continuada, os alunos faltosos, é fundamental modificar o entendimento do significado da presença estudantil nas atividades escolares. Embora a LDB considere que a frequêencia do aluno a um mínimo de $75 \%$ das aulas é obrigatória para a promoção do mesmo, isto năo quer dizer que faltar até $25 \%$ das atividades escolares seja um direito do aluno. Antes, qualquer falta à escola de ensino fundamental de certa forma fere o direito da sociedade de ter seus cidadăos sendo educados. Assim, cumpre-se trabalhar para eliminar o grande número de ausências às atividades escolares, conscientizando os alunos das conseqüencias que suas faltas às aulas the acarretariam, cabendo ao Poder Público zelar pela freqüência da criança ou adolescente ao ensino fundamental (ECA, artigo 54, parágrafo terceiro).

$\mathrm{Na}$ hipótese de reiteraçăo de faltas injustificadas, o aluno faltoso está obrigatoriamente sujeito às medidas de proteçăo estabelecidas pelo Estatuto da Criança e do Adolescente (artigos 98, 101, 136), cabendo ao dirigente da unidade escolar comunicar o fato ao Conselho Tutelar para as devidas providências (ECA - Estatuto da Criança e do Adolescente, artigo 56). Daí a importância de medidas de 
recuperação de ausências através da realização de tarefas várias para evitar uma medida de exclusão escolar incompatível com o princípio constitucional do direito à educação fundamental. Entretanto, esgotadas todas as medidas tutelares e as de recuperaçăo de ausências concentradas ou distribuídas ao longo do ano letivo, o aluno permanece classificado na mesma série, podendo, contudo, ser submetido a procedimento de reclassificação no inćcio do próximo ano letivo, se demonstrar desempenho pedagógico compatível com o prosseguimento de estudos na série seguinte.

Todos os pontos apresentados representam o compromisso de buscar novas formas de trabalho pedagógico mais adequadas ao presente contexto cultural que vem cercando a escola e trabalhar para a criação de novos motivos escolares para todos os alunos, dentro de um projeto político-educacional de construir uma escola realmente nova. 

